\title{
The Mega Distributed Lag Model
}

\author{
Mario Arturo Ruiz Estrada', Evangelos Koutronas², Ross Knippenberg ${ }^{3}$
}

\begin{abstract}
This paper attempts to describe the graphical behavior of the distributed lag model in an infinite coordinate space. The "mega distributed lag model" (MDL) is a mathematical framework that can examine the simultaneous interrelationships between all involved variables. The multidimensional graphical setting simultaneously reveals all non-linear exposure-response dependencies and delayed effects between lagged and dependent variables — which two-dimensional figures overwhelmingly fail to capture. Under the Omnia Mobilis assumption, each distribution lag function is indexed with respect to time and space. The Mega distributed lag model observes multiple trends in full motion, the final output (determinant) of which is called "the JIM-coefficient". Hence, this paper tries to analyze different approaches of lag distribution models that can help in the construction of our new model. The mega distributed lag model" (MDL) is moving from the uses of the classic 2-dimensional and 3-dimensional graphical modeling to a multidimensional graphical modeling in Econometrics. Finally, this model is an extension of those explored earlier in the field of econographicology.
\end{abstract}

KEY WORDS: $\quad$ Econographicology, Distributed lag model, Multi-Dimensional graphs and Multi-Dimensional geometry

JEL Classification: C10

${ }^{1}$ University of Malaya - Economics, Malaysia; ${ }^{2}$ University of Malaya - Social Security Research Centre (SSRC), Malaysia;

${ }^{3}$ American Veterinary Medical Association - Economics, United States

\section{Introduction}

Dynamic specification attempts to capture the hidden dynamics derived by the observed time-series data in a postulate theoretical model (Hendry, Pagan, \& Sargan, 1984). The general approach in a trend stationary process has been to de-trend the series and to model the de-trended series as distributed lag or autoregressive distributed lag (ADL) models. A lag distribution function gives a magnitude of the coefficient of a lagged explanatory variable, expressed as a function of the lag, and extra information is injected into the

Correspondence concerning this article should be addressed to: Mario Arturo Ruiz Estrada, University of Malaya - Economics, KL53600, Malaysia.T:+60379673728. E-mail:marioruiz@um.edu.my estimation procedure. Estimation and inference concerning the long-run properties of the model are then carried out using standard asymptotic normal theory. A wide variety of specifications has been suggested for this purpose, including arithmetic, inverted V, Almon, Shiller, harmonic geometric, Pascal, rational, gamma, and exponential (Kennedy, 1998). A distributed-lag model is a dynamic model in which the effect of a regressor $\mathrm{x}$ on $\mathrm{y}$ occurs over time rather than all at once. Based on a Hendry-style (Hendry et al., 1984) autoregressive distributed lag equation (see Appendix A), considered the general form of one dependent variable and one explanatory variable, the model takes the form

$\mathrm{y}_{\mathrm{t}}=\alpha+\beta(\mathrm{L}) \mathrm{x}_{\mathrm{t}}+\mathrm{u}_{\mathrm{t}}=\alpha+\sum_{\mathrm{s}=0}^{\infty} \beta_{\mathrm{s}} \mathrm{x}_{\mathrm{t}-\mathrm{s}}+\mathrm{u}_{\mathrm{t}}$ 
where $x_{t}$ is exogenous for $t=1, \ldots, T$, and $u_{t}$ is the stationary error term, i.i.d. $\left(0, \sigma^{2}\right)$. This form is very similar to the infinite-moving-average representation of an ARMA process, except that the lag polynomial on the right-hand side is applied to the explanatory variable $\mathrm{x}$ rather than to a white-noise process $\varepsilon$. The individual coefficients $\beta$ are called lag weights and collectively comprise the lag distribution. They define the pattern of how $\mathrm{x}$ affects $\mathrm{y}$ over time.

The distributed lag concept was known among economists through the pioneering work of Irving Fisher (1930) on the relationship between the nominal interest rate and the expected inflation rate. However, its application in econometrics was launched by Koyck's (1954) geometric distributed lag model in a study of investment. The geometric distributed lag model was based on the notion of adaptive expectations hypothesis. It could estimate the autoregressive model with an auto-correlated error. One disadvantage of this lag structure is that coefficients of the lagged explanatory variables continually decline; they cannot first rise and then decline, a pattern thought by many to be a priori attractive and one that should not be ruled out of consideration. One way of addressing this problem is to allow unrestricted coefficients on the first few lagged variables and then impose a geometric pattern (Kennedy, 1998). The above mechanism was extensively applied in numerous empirical studies: Cagan's (1956) study of monetary aspects of hyperinflation; Friedman's (1957) study of consumption behavior; Nerlove's (1958a) study of supply and demand decisions (cobweb model); Solow's (1960) study of consumption behavior; and Jorgenson's (1966) study of investment.

At about the same time, Almon (1965) provided a polynomial generalization of Fisher's (1937) arithmetic lag distribution. In this technique, the n coefficients of the lagged explanatory variables are assumed to lie on a polynomial of order $r$. This allows for a flexible lag structure reduction in the number of the parameters that require estimation if $r+1$ is less than $\mathrm{n}$. It can be viewed as imposing a specific set of linear constraints on OLS estimation. Several studies have investigated the effects of misspecifying the lag length or polynomial degree in the Almon lag model (Frost, 1975; Harper, 1977; Schmidt \& Sickles, 1975;
Schmidt \& Waud, 1973; Terasvirta, 1976; Thomas, 1977; Trivedi, 1970; Trivedi \& Pagan, 1979).

Almon polynomial lag distribution was later extended further by Shiller (1973). Shiller's distributed lag is a variant of this in which these restrictions are stochastic, incorporated via the mixed estimation technique; the coefficients of the lagged explanatory variable lie close to, rather than on, a polynomial. The main problem with the Almon lag is determining $n$ and $\mathrm{r}$; pretesting is usually employed for this purpose, resulting in estimators with unknown properties.

Mitchel and Speaker (1986) introduced a reduced form of the model via a linear transformation of the polynomial lag model, estimated the reduced-form parameters, and recovered estimates of the structural parameters via an inverse linear transformation of the reduced-form parameter estimates. The so-called polynomial inverse lag model has flexible shape and can be easily estimated linearly as long as the lag operator is invertible (the polynomial roots inside/outside the unit root circle) (Kasparis, 2008). Other forms of dynamic specification considered in the literature included the partial adjustment model (Eisner \& Strotz, 1963; Nerlove, 1958b) and the multivariate flexible accelerator model (Treadway, 1971) and Sargan's (1964) work on econometric time series.

The most known parameterization of the (ADL) model is the error-correction model (EC). The use of an error correction mechanism for non-stationary variables is equivalent of performing co-integration (Dickey \& Fuller, 1981). By differencing and forming a linear combination of the non-stationary data, all variables are transformed equivalently into an EC model with stationary series only (Hassler \& Wolters, 2006). Phillips (1954; 1957) introduced EC models to economics. Sargan (1964) used them to estimate structural equations with auto correlated residuals, and Hendry popularized their use in econometrics in a series of papers. A survey on specification, estimation and testing of EC models is given by Alogoskoufis and Smith (1995).

Current literature, however, has identified three major shortcomings (Kim, Fraser, \& Hyndman, 2010). First, point estimates of the long-run response are often extremely disparate (Askari \& Cummings, 1977; Marquez \& McNeilly, 1988). Second, the sampling variability of the long-run response estimator is 



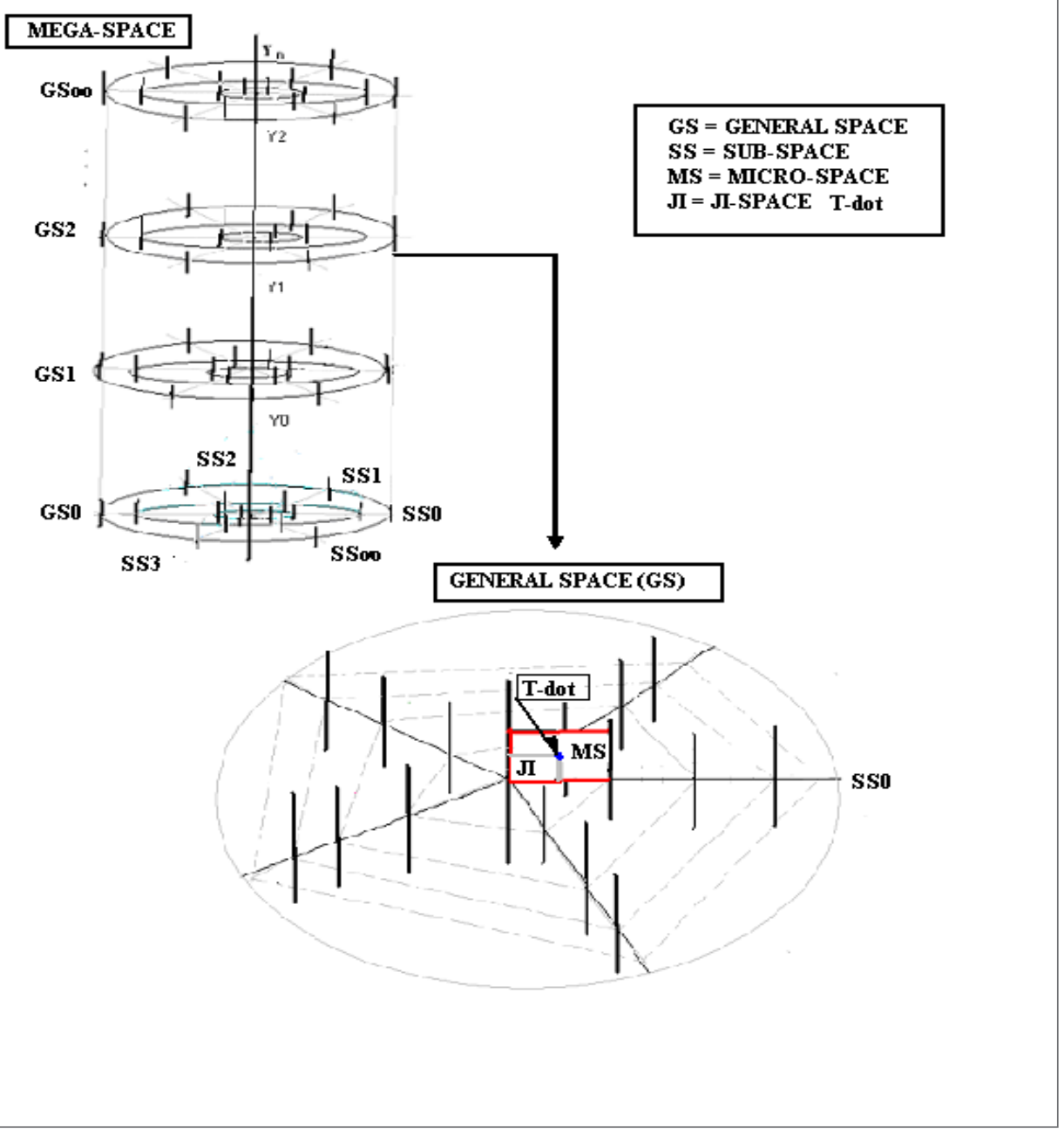

Figure 1. The Infinity Coordinate Space (Specific Approach)

uted lag functions to simultaneously observe multiple trends in full motion (see Figure 2).

The final output of the mega distributed lag model is based on the result of a single determinant $(\Delta)$ from a matrix with $\mathrm{m}$ rows and $\mathrm{n}$ columns (see Expression 2.6). This matrix accounts for the final results of all distributed lag functions from different micro-spaces under different general levels and sub-levels of analysis. The final output (determinant) is labelled "the JIM-coefficient". This JIM-coefficient is a measure encompassing all of the information from the analysis, and so can be 


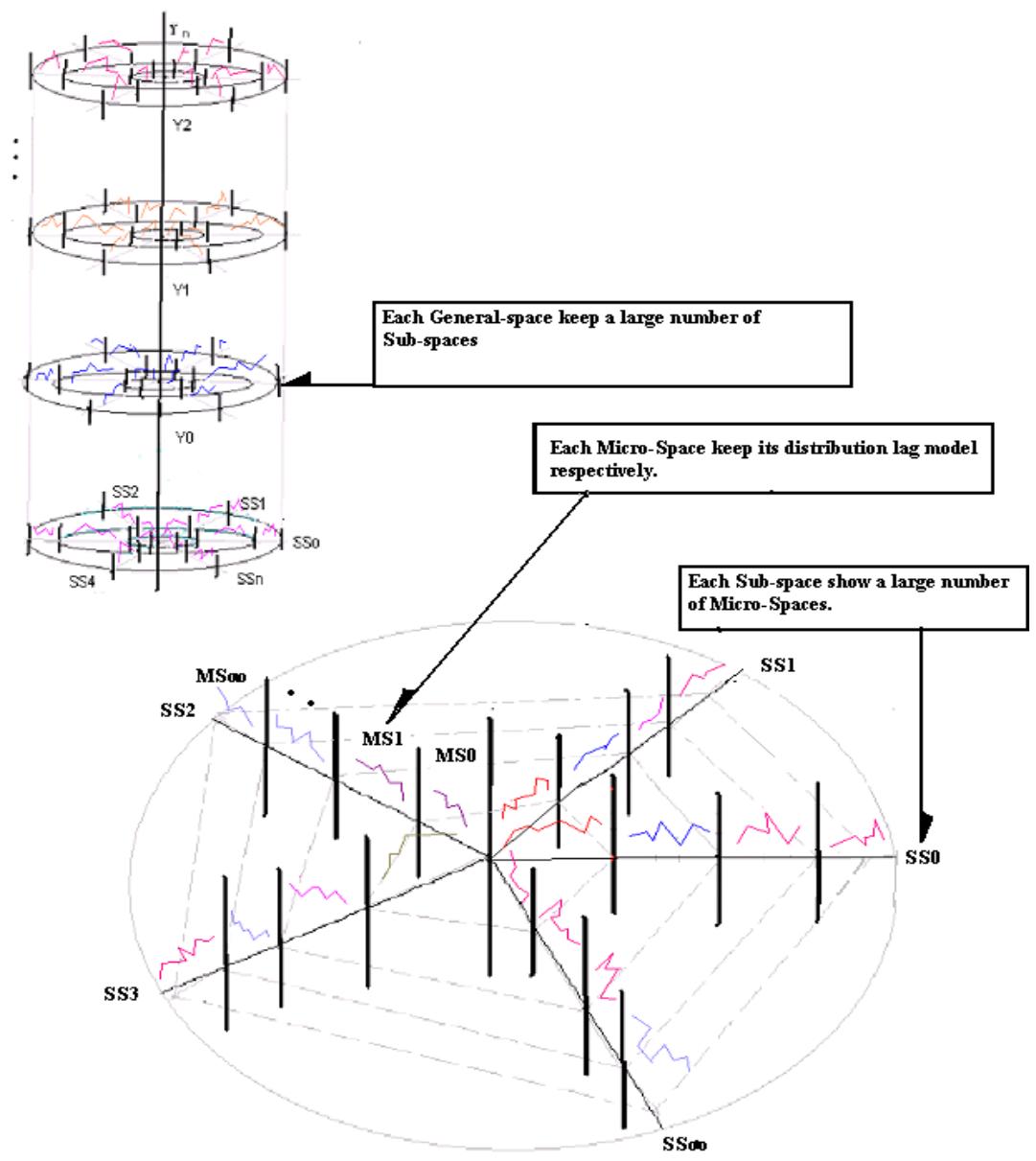

Figure 2. The Mega Distributed Lag Model

considered the final result from the mega distribution lag model.

\section{General-Space "n"}

$\mathrm{Y}_{\text {tp(GV:SV:MV:JV) }}^{\mathrm{n}}=\alpha_{(\mathrm{GV}: S V: M V: J V)+} \beta^{\mathrm{LD}}{ }_{(\mathrm{GV}: S V: M V: I I V)} \mathrm{X}^{\mathrm{tp} / 0}{ }_{(\mathrm{GV}: S V: M V: I V)}+$ $+\beta_{(\mathrm{GV}: S V: M V: J V)}^{\mathrm{L} 1} \mathrm{X}_{(\mathrm{GV}: S V: M V: J I V)-1}^{\mathrm{tp} / 1}+\ldots+$

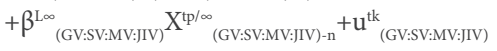

Where

$\mathrm{JIV}=\{0,1,2 \ldots \infty\}$

$\mathrm{n}=\{0,1,2 \ldots \infty\}$

Therefore,

$$
\begin{aligned}
& \mathrm{E} / \mathrm{U}^{\mathrm{tk}} /=\mathrm{K}_{\mathrm{o}} \\
& \operatorname{Var}\left(\mathrm{U}^{\mathrm{tk}}\right)=\sigma_{(\mathrm{GV}: S V: M V: I V)}^{\mathrm{i}} \\
& \operatorname{Cov}\left(\mathrm{U}^{\mathrm{tk}}, \mathrm{U}_{\mathrm{s}}^{\mathrm{tk}}\right)=\sigma_{(\mathrm{GV}: S V: M V: I V)}^{\mathrm{i}}
\end{aligned}
$$




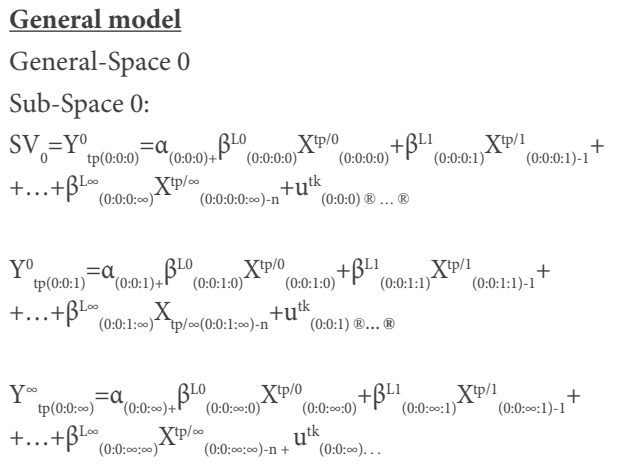

Sub-Space $\infty$ :

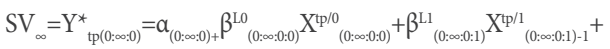
$+.+\beta_{(0: \infty: 0 ; \infty)}^{\mathrm{L} \infty} \mathrm{X}_{(0 ; \infty): 0 ; \infty)-\mathrm{n}}^{\mathrm{tp} / \infty}+\mathrm{u}^{\mathrm{tk}}{ }_{(0 ; \infty): 0)(\ldots)(B)}$

$\mathrm{Y}_{\mathrm{tp}(0 ; \infty: 1)}^{0}=\alpha_{(0 ; \infty: 1)+} \beta_{(0 ; \infty: 1: 0)}^{\mathrm{L} 0} \mathrm{X}_{(0 ; \infty: 1: 0)}^{\mathrm{tp} / 0}+\beta_{(0: \infty: 1: 1)}^{\mathrm{Ll}} \mathrm{X}_{(0 ; \infty: 1: 1)-1}^{\mathrm{tp} / 1}+$ $+\ldots+\beta_{(0 ; \infty: 1 ; \infty)}^{\mathrm{L} \infty} \mathrm{X}_{(0 ; \infty ; 1 ; \infty)-\mathrm{n}}^{\mathrm{tp} / \infty} \mathrm{u}_{(0 ; \infty ; 1) \circledast \ldots]}^{\mathrm{tk}}$

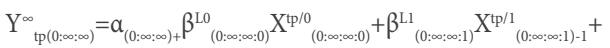
$+\ldots+\beta_{(0 ; \infty ; \infty ; \infty)}^{\mathrm{L} \infty} \mathrm{X}_{(0 ; \infty \infty \infty ; \infty)-\mathrm{n}}^{\mathrm{tp} / \infty} \mathrm{u}_{(0 ; \infty) \infty)}^{\mathrm{tk}}$

\section{General-Space $\infty$}

Sub-Space 0:

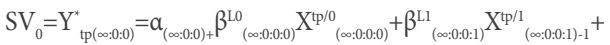

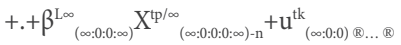

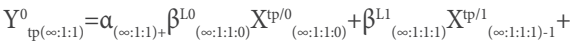
$+\ldots+\beta_{(\infty: 1: 1: \infty)}^{\mathrm{L} \infty} \mathrm{X}_{(\infty ; 1: 1: \infty)-\mathrm{n}}^{\mathrm{tp} / \infty}+\mathrm{u}^{\mathrm{tk}}(\infty: 1: 1)(\ldots)$

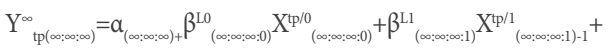
$+.+\beta_{(\infty ; \infty ; \infty ; \infty)}^{\mathrm{L} \infty \infty} \mathrm{X}_{(\infty ; \infty ; \infty ; \infty)-\mathrm{n}+}^{\mathrm{tp} / \infty} \mathrm{u}^{\mathrm{tk}}{ }_{(\infty ; \infty ; \infty) \ldots}$

Sub-Space $\infty$ :

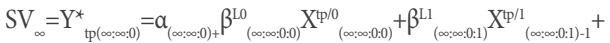

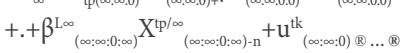

$\mathrm{Y}_{\operatorname{tp}(\infty ; \infty ; 1)}^{0}=\alpha_{(\infty ; \infty ; 1)+} \beta_{(\infty ; \infty): 1: 0)}^{\mathrm{L} 0} \mathrm{X}_{(\infty ; \infty): 1: 0)}^{\mathrm{tp} / 0}+\beta_{(\infty ; \infty): 1: 1)}^{\mathrm{L} 1} \mathrm{X}_{(\infty ; \infty: 1: 1)-1}^{\mathrm{tp} / 1}+$

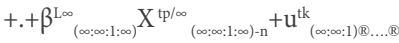

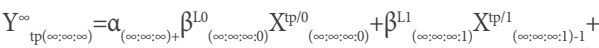
$+.+\beta^{\mathrm{L} \infty}{ }_{(\infty ; \infty) \infty \infty \infty)} \mathrm{X}^{\mathrm{tp} / \infty}{ }_{(\infty ; \infty) \infty \infty \infty \infty)-\mathrm{n}}+\mathrm{u}^{\mathrm{tk}}{ }_{(\infty ; \infty) \infty ; \infty)}$

$$
\Delta=\left(\begin{array}{lc}
\mathrm{GV}_{0}=\mathrm{SV}_{0}{ }^{\circledR} \mathrm{SV}_{1}{ }^{\circledR} \ldots & \mathrm{SV}_{\infty \ldots} \\
\cdot & \cdot \\
\cdot & \cdot \\
\mathrm{GV} \infty=\mathrm{SV}_{0}\left(\mathrm{SV}_{1}{ }^{\circledR} \ldots \mathrm{SV}_{\infty} \ldots\right.
\end{array}\right)
$$

Variables:

$\mathrm{GV}=$ General variable, $\mathrm{SV}=\mathrm{Sub}$-variable, $\mathrm{MS}=\mathrm{Mi}-$ cro-variable, JIV = JI-variable, $\mathrm{tp}=$ Partial Time, $\mathrm{tk}=$ Constant Time, ${ }^{\circledR}=$ Window refraction

\section{Concluding Remarks}

In conclusion, previous attempts at graphing multi-dimensional behavior in the distributed lag model have stopped at two dimensions. Because of this, we advocate the use of an alternative general distributed lag model, which we call "the mega distributed lag model". This paper has developed the framework for extending those representations of distributed lag models to an arbitrarily large number of dimensions. The advantage of doing so is to aid in the identification of abnormally strong relationships between the lagged variables and the dependent variable, which two-dimensional figures overwhelmingly fail to capture. Multi-Dimensional Coordinate Space framework treats each dimension uniformly at the cost of coarse representation (Ruiz Estrada, 2011b), enabling us to delve deeper into understanding the behavior of an infinite distributed lag model. Hence, the 2-dimensional Cartesian coordinate plane and the 3-dimensional coordinate space are limited in their ability to visualize a large number of variables simultaneously in the same graphical space and time framework.

\section{References}

Almon, S. (1965). The distributed lag between capital appropriations and net expenditures Econometrica, 33(1), 178-196.

Alogoskoufis, G., \& Smith, R. (1995). On error correction models: Specificaton, interpretation, estimation. In L. Oxley, D. A. R. George, C. J. Roberts \& S. Sayer (Eds.), Surveys in Econometrics (pp.139170). Oxford, UK: Blackwell Publishers.

Askari, H., \& Cummings, T. (1977). Estimating agricultural supply response with Nerlove Model: A Survey International Economic Review, 18(2), 257-292. 
Cagan, P. (1956). The monetary dynamics of hyperinflation. In M. Friedman (Ed.), Studies in the quantity theory of money (pp. 25-117). Chicago, IL: University of Chicago Press.

Dickey, D. A., \& Fuller, A. W. (1981). Likelihood ratio statistics for autoregressive time series with a unit root. Econometrica, 49(4), 1057-1072.

Eisner, R., \& Strotz, R. H. (1963). Determinants of business investment. In Commission on Money and Credit. American Bankers Association (Eds.), Impacts of Monetary Policy (pp. 59-337). Englewood Cliffs, NJ: Prentice-Hall.

Fisher, I. (1930). The theory of interest. New York, NY: Kelley and Millman.

Fisher, I. (1937). Note on a short-cut method for calculatin distributed lags. Bulletin de l'Institut International de Statistique, 29, 323-327.

Focareli, D. (2005). Bootstrap bias-correction procedure in estimating long-run relationships from dynamic panels, with an application to money demand in the euro area. Economic Modelling, 22(2), 305-325.

Friedman, B. M. (1957). A Theory of the consumption function. Princeton, NJ: Princeton University Press.

Frost, P. A. (1975). Some properties of the Almon lag technique when one searches for degree of polynomial and lag. Journal of the American Statistical Association, 70(351a), 606-612.

Harper, C. P. (1977). Testing for the existence of a lagged relationship within Almon's method. Review of Economics and Statistics, 59(2), 204-210.

Hassler, U., \& Wolters, J. (2006). Autoregressive distributed lag models and cointegration. Allgemeines Statistisches Archiv, 90, 59-74.

Hendry, D. F., Pagan, A. R., \& Sargan, J. D. (1984). Dynamic Specification. In Z. Griliches \& M. Intriligator (Eds.), Handbook of Econometrics (Vol. II, pp. 1025-1100): Amsterdam: North Holland.

Jorgenson, D. W. (1966). Rational distributed lag functions. Econometrica, 34(1), 135-149.

Kasparis, I. (2008). A Simple Proof for the Invertibility of the Lag Polynomial Operator. (Discussion Paper No. 2008-06). University of Cyprus. Department of Economics.

Kennedy, P. (1998). A Guide to Econometrics (3rd ed.). Cambridge, Massachusetts, MA: The MIT Press.
Kim, J., H., Fraser, I., \& Hyndman, R. J. (2010). Improved Interval Estimation of Long Run Response from a Dynamic Linear Model: A Highest Density Region Approach (Working Papers 2010.06). School of Economics. La Trobe University.

Koyck, L. M. (1954). Distributes lags and investment analysis. Amsterdam: North Holland.

Li, H., \& Maddala, G. S. (1999). Bootsrap variance estimation of non-linear functions of parameters: An application to long-run elasticities of energy demand. The Review of Economics and Statistics, 81(4), 728-733.

Marquez, J., \& McNeilly, C. (1988). Income and price elasticities for exports of developing countries. The Review of Economics and Statistics, 70(2), 306-314.

Mitchell, D. W., \& Speaker, P. J. (1986). A Simple, flexible distributed lag technique: The polynomial inverse lag. Journal of Econometrics, 31(3), 329-340.

Nerlove, M. (1958a). Adaptive expectations and the cobweb phenomena. Quarterly Journal of Economics, 72(2), 227-240.

Nerlove, M. (1958b). Distributed Lags and Demand Analysis (Agriculture Handbook No. 141). Agriculture. Washington, D.C.: U.S. Department of Agriculture.

Pesaran, M. H., \& Zhao, Z. (1999). Bias reduction in estimating long-run relationships from dynamic heterogeneous panels. In C. Hsiao, K. Lahiri, L. F. Lee \& M. H. Pesaran (Eds.), Analysis of panels and limited dependent variables: A volume in honour of G. S. Maddala (pp. 297-321). Cambridge, UK: Cambridge University Press.

Phillips, A. W. (1954). Stabilization policy in a closed economy. Economic Journal, 64(254), 290-323.

Phillips, A. W. (1957). Stabilization policy and the time form of lagged responses. Economic Journal, 67(266), 265-277.

Ruiz Estrada, M. A. (2011a). Policy modeling: Definition, classification and evaluation. Journal of Policy Modeling, 33(4), 523-536.

Ruiz Estrada, M. A. (2011b). Multi-Dimensional coordinate spaces. International Journal of the Physical Sciences, 6(3), 340-357.

Sargan, J. D. (1964). Wages and prices in the United Kingdom: A study in econometric methodology. In P. E. Hart, G. Mills \& J. K. Whitaker (Eds.), Econometric Analysis for National Economic Planning (pp. 25-54). London, UK: Butterworths. 
Schmidt, P., \& Sickles, R. (1975). On the Efficiency of the Almon Lag Technique. International Economic Review, 16, 792-795.

Schmidt, P., \& Waud, R. N. (1973). The Almon Lag Technique and the Monetary versus Fiscal Policy Debate. Journal of American Statistical Association, 68(341), 11-19.

Shiller, R. J. (1973). A distributed lag estimator derived from smoothness priors. Econometrica, 41(4), 775-788.

Solow, R. (1960). On a family of lag distributions. Econometrica, 28(2), 393-406.

Terasvirta, T. (1976). A note on bias in the Almon distributed lag estimator. Econometrica, 44(6), 13171322.

Thomas, J. J. (1977). Some problems in the use of Almon's technique in the estimation of distributed lags. Empirical Economics, 2(3), 175-193.

Treadway, A. B. (1971). The rational multivariate flexible accelarator. Econometrica, 39(5), 845-855.

Trivedi, P. K. (1970). A note on the application of Almon's method of calculating distributed lag coefficients. Metroeconomica, 22(3), 281-286.

Trivedi, P. K., \& Pagan, A. R. (1979). Polynomial distributed lags: A unified treatment. Economic Studies Quarterly, 30, 37-49.

Wahba, G. (1969). Estimation of the Coefficients in a Multidimensional Distributed Lag Model. Econometrica, 37(3), 398-407. 


\section{Appendix A}

Consider the autoregressive distributed lag model of order $\mathrm{p}$ and $\mathrm{q}, \operatorname{ADL}(\mathrm{p}, \mathrm{q})$, defined for a scalar variable $y_{t}$ as

$$
\mathrm{y}_{\mathrm{t}}=\alpha+\sum_{\mathrm{i}=1}^{\mathrm{p}} \gamma_{\mathrm{i}} \mathrm{y}_{\mathrm{t}-\mathrm{i}}+\sum_{\mathrm{i}=0}^{\mathrm{q}} \beta_{\mathrm{i}} \mathrm{x}_{\mathrm{t}-\mathrm{i}}+\eta_{\mathrm{t}}
$$

where $\eta_{t}$ is a scalar independent white noise and $x_{t}$ is a K-dimensional column stationary variable vector process. The sequence $\left\{\eta_{\mathrm{t}}\right\}$ is a white-noise process if for each period $t$,

$$
\begin{gathered}
\mathrm{E}\left(\eta_{\mathrm{t}}\right)=\mathrm{E}\left(\eta_{\mathrm{t}-1}\right)=\ldots=0 \\
\mathrm{E}\left(\eta_{\mathrm{t}}^{2}\right)=\mathrm{E}\left(\eta_{\mathrm{t}-1}^{2}\right)=\ldots=\sigma^{2} \\
\mathrm{E}\left(\eta_{\mathrm{t}} \eta_{\mathrm{t}-\mathrm{s}}\right)=\mathrm{E}\left(\eta_{\mathrm{t}-\mathrm{j}} \eta_{\mathrm{t}-\mathrm{j}-\mathrm{s}}\right)=0 \text { for all } \eta
\end{gathered}
$$

As long as the error term $\eta_{t}$ is a white noise process, the ADL model can be estimated consistently by ordinary least squares. Using the lag operator $\mathrm{L}$ applied to each component of a vector, $\mathrm{L}^{\mathrm{k}} \mathrm{x}_{\mathrm{t}}=\mathrm{x}_{\mathrm{t}-\mathrm{k}}$ (lag of a constant: $\mathrm{L} \alpha=\alpha$ ), it is convenient to define the lag polynomial $\gamma(\mathrm{L})$ and the vector polynomial $\beta(\mathrm{L})$

$$
\begin{gathered}
\mathrm{a}(\mathrm{L})=\alpha \\
\gamma(\mathrm{L})=\left(1+\gamma_{1} \mathrm{~L}+\gamma_{2} \mathrm{~L}^{2}+\ldots+\gamma \mathrm{L}^{\mathrm{p}}\right) \\
\beta(\mathrm{L})=\left(\beta_{0}+\beta_{1} \mathrm{~L}+\beta_{2} \mathrm{~L}^{2}+\ldots+\beta_{\mathrm{q}} \mathrm{L}^{\mathrm{q}}\right)
\end{gathered}
$$

Rearranging the lag polynomial $\gamma(\mathrm{L}) \mathrm{y}_{\mathrm{t}}$, equation (A1) takes the straightforward form

$$
\gamma(\mathrm{L}) \mathrm{y}_{\mathrm{t}}=\mathrm{a}+\beta(\mathrm{L}) \mathrm{x}_{\mathrm{t}}+\eta_{\mathrm{t}}
$$

Equation (A2) implies that the current value of y depends on all previous values of $a, x$, and $\eta$. The dynamic effects correspond to the lag weights of the infinite moving average representation

$\frac{\partial \mathrm{y}_{t+\mathrm{i}}}{\partial \mathrm{x}_{\mathrm{t}}}=\frac{\partial \mathrm{y}_{\mathrm{t}}}{\partial \mathrm{x}_{\mathrm{t}-\mathrm{i}}}=\beta_{\mathrm{i}}$

Note that the first equation in (A3) requires that the time-series relationship between $y$ and $x$ be stationary, so we can think of $\beta_{i}$ either as the effect of current $x_{t}$ on future $y_{t+i}$ or as the effect of past $x_{t-i}$ on current $y_{\mathrm{t}}$. In order to obtain stability, it is maintained that

$\gamma(\varphi)=0 \Rightarrow|\varphi|>1 \forall \varphi \in N$

Under this condition there exists an absolutely summable infinite expansion of the inverted polynomial $\gamma^{-1}(\mathrm{~L})$ :

$\gamma^{-1}(\mathrm{~L})=\frac{1}{\gamma(\mathrm{L})}=\sum_{\mathrm{j}=0}^{\infty} \gamma_{\mathrm{j}}^{*} \mathrm{~L}^{\mathrm{j}}, \quad \sum_{\mathrm{j}=0}^{\infty}\left|\gamma_{\mathrm{j}}^{*}\right|<\infty$

Invertibility of $\gamma(\mathrm{L})$ hence yields the following representation:

$\mathrm{y}_{\mathrm{t}}=\frac{\beta(\mathrm{L})}{\gamma(\mathrm{L})} \mathrm{x}_{\mathrm{t}}+\psi_{\mathrm{t}}, \quad \gamma(\mathrm{L}) \psi_{\mathrm{t}}=\eta_{\mathrm{t}}$

where $\eta_{\mathrm{t}}$ has a stable autoregressive structure of order p. Expanding $\gamma^{-1}(\mathrm{~L})$ provides an infinite distributed lag representation,

$y_{t}=\left(\sum_{j=0}^{\infty} \gamma_{j}^{*} L^{j}\right)\left(\sum_{j=0}^{q} \beta_{j}^{*} L^{j}\right)^{\prime} x_{t}+\psi_{t}=\sum_{j=0}^{\infty} \omega_{j}^{\prime} x_{t-j}+\psi_{t}$

where $\omega_{j}$ are the vectors of dynamic multipliers derived by the method of indetermined coefficients. The vector of long-run multipliers of the $\operatorname{ADL}(p, n)$ model may therefore be easily computed from:

$\xi=\frac{\beta(1)}{\gamma(1)}=\sum_{\mathrm{j}=0}^{\infty} \omega_{\mathrm{j}}$

By re-arranging the x's one obtains with $\Delta=1-\mathrm{L}$ :

$\mathrm{y}_{\mathrm{t}}=\sum_{\mathrm{i}=1}^{\mathrm{p}} \gamma_{\mathrm{i}} \mathrm{y}_{\mathrm{t}-\mathrm{i}}+\gamma(1) \xi^{\prime} \mathrm{x}_{\mathrm{t}}-\sum_{\mathrm{i}=0}^{\mathrm{q}-1}\left(\sum_{\mathrm{j}=\mathrm{i}+1}^{\mathrm{q}} \beta_{\mathrm{j}}\right)^{\prime} \Delta \mathrm{x}_{\mathrm{t}-\mathrm{i}}+\psi_{\mathrm{t}}$

where $y_{t}$ is related to its own past, to contemporaneous $\mathrm{x}_{\mathrm{t}}$ and differences $\Delta \mathrm{x}_{\mathrm{t}-\mathrm{i}}$. This is called the error correction model (ECM). 
